Encounters on Education

Volume 4, Fall 2003 pp. 1 - 10

\title{
Introduction
}

\section{Citizenship education: Theory, research and practice}

\section{Daniel Schugurensky and J ohn P. Myers}

Ontario Institute for Studies in Education of the University of Toronto (OISE/UT)

HIS SPECIAL ISSUE ON CITIZENSHIP EDUCATION IS THE RESULT of a collaborative effort of Encounters on Education and the Citizenship Education Research $\mathrm{N}$ etwork (CERN ). The articles in this volume issue are revised versions of papers that were presented and discussed at the third and fourth CERN conferences, held in Toronto in 2002 and in $\mathrm{H}$ alifax in 2003, respectively.

The Citizenship Education Research N etwork was created in 1998 to provide a forum for researchers, policy makers and practitioners in the field of citizenship education. In its few years of existence, CERN has grown beyond expectations, rapidly becoming a meeting place for citizenship education researchers, policy-makers and citizenship educators. Although CERN originated in Canada (and is affiliated with the Canadian Society for Studies in Education), it is pertinent to note that many of its members conduct international research, and that its international membership has expanded in the last two years. In this context, we are very pleased that these papers are published in Encounters on Education, a trilingual journal that aims at generating a dialogue among education researchers from C anada, Spain and Latin America. T he articles are printed in the language in which they were submitted.

C itizenship education is a vast field that includes a wide range of philosophical, political and ideological perspectives, and of pedagogical approaches, goals and practices. At the most abstract level of discourse, there is a general consensus that the main purpose of citizenship education is the development of good democratic citizens. In terms of implementation, which includes educational policies, curriculum development and pedagogical strategies, this purpose is expressed in different ways. Indeed, like other educational fields, citizenship education has conservative and progressive orientations. Citizenship education can be used as a tool for maintaining the status quo, but also for empowering individuals and groups to struggle for emancipatory change. 
W hile citizenship education practices are situated somewhere along a continuum between these two orientations, they tend to gravitate towards one or the other.

The conservative orientation to citizenship education privileges the reproduction of the existing socio-economic order. From this point of view, capitalism and democracy are perfect complements and it would be impossible to conceive of one without the other. Among its purposes are instilling national loyalty, obedience to authority, voluntary service and the assimilation of immigrants. In terms of content, conservative citizenship education deals primarily with national narratives, historical and geographical facts, and the functioning of government institutions. From this perspective, citizenship education should accept existing social structures, develop moral character and ensure social cohesion. Good citizens are conceptualized as good producers, good consumers, and good patriots. Representative democracy is the ultimate model, and voting is the most important expression of citizen participation.

The progressive orientation to citizenship education privileges societal transformation and social justice. This tradition identifies an inherent tension between capitalism and democracy, as the former generates inequalities and exclusion, and the latter attempts to reduce them. Among its purposes are to nurture cosmopolitanism, critical analysis, political engagement and cross-cultural respect and understanding. Citizenship education should be primarily concerned with emancipation, which implies the development of active, informed and critical citizens who can participate effectively in civic life and in the affairs of the state. From this perspective, citizenship education should examine gender, race and class structures, promote social justice and diversity, and prepare citizens for inclusive political processes of deliberation and decision-making. Good citizens are conceptualized as compassionate, politically engaged, concerned for social justice and the environment, tolerant of others, willing and able to dialogue, and active participants in public life. Following the insights of feminism and participatory democracy, citizenship should recognize private as well as public activities, and democracy should include greater public participation in decision making than casting a vote every four years. In the progressive orientation, representative and participatory democracy can and should complement each other, and citizens' main task is to further democratize our imperfect democracies.

Given the history of twentieth century education, it is plausible that the tension between these two orientations will continue in the twenty-first century. This is expected because in every community there are competing proposals about the meaning of citizenship, the qualities of a good citizen, the characteristics of the good society, and the strategies to move toward such a society. These competing proposals inform different conceptions of what citizenship education ought to be. Given this situation, policy makers, researchers and citizenship educators will continue to face political, ethical and pedagogical choices. These choices will be the subject of passionate debates and dialogues, agreements and disagreements. In the spirit of contributing to this conversation, we would like to advance seven propositions for citizenship education in the twenty-first century. These propositions attempt to bring together some of the concerns, visions and strategies that are being discussed by progressive citizenship educators around the world. 


\section{Seven proposals for twenty-first century citizenship education}

\section{From passiveto active citizenship}

The first proposition is that citizenship education should not only promote passive citizenship (most frequently expressed in the uncritical acquisition of information about historical, legal and institutional facts), but also active citizenship, which is about revitalizing democratic public life, including school life. The development of informed citizens is a necessary but insufficient condition for the development of democratic societies. Citizenship education should nurture well-informed citizens who are also caring, responsible and engaged, and have critical thinking skills. Promoting active citizenship also implies expanding current programs of community service, so that they include not only charitable activities and volunteer work, but also active involvement with democratic institutions, with political proposals and with contemporary public dialogues.

\section{From national citizenship to planetary/ecological citizenship}

The second proposition is that citizenship education should foster allegiance to the Earth as a single community. This does not mean to ignore the relevance of national identity and sovereignty, particularly in the current context of neoliberal globalization, neocolonial dynamics and unilateralism. For instance, Canada's status as a sovereign nation-state allows it to protect its universal healthcare and to take a stand in support of peace in the face of pressures to go to war. H owever, we should also consider that important issues such as peace, human rights and environmental degradation are global in scope and must be addressed collectively and cooperatively. In this context, an education for planetary/ecological citizenship can help learners to move from an egocentric and sociocentric perspective to one that privileges the planetary ecological system and evaluates the implications of human actions for future generations.

A planetary citizenship education within an ecological context recognizes our finite resources, raises awareness about first world over-consumption of non-renewable resources, and addresses the race to the bottom in terms of corporate environmental behavior and government policies (e.g. the rejection of the Kyoto accord). This education al so stresses the centrality of universal human rights as an inherent aspect of citizenship. Finally, education for planetary/ecological citizenship would nurture the development of a cosmopolitan democratic spirit that transcends the boundaries of particular nation-states, promoting multilateralism and strengthening international institutions like the $U$ nited $\mathrm{N}$ ations.

From recognizing cultural diversity to fostering intercultural societies

The third proposition is that citizenship education should deepen existing multicultural approaches by fostering the development of intercultural societies. M ulticulturalism constituted a great improvement over the previous educational emphasis on the assimilation and acculturation of immigrants and indigenous peoples. H owever, multicultural education has not yet been developed to its potential. W hile critical traditions of multicultural education (such as critical race theory) have made valuable 
contributions, they have been relatively marginal in a field that often ignores issues of power and oppression. Indeed, mainstream multicultural education tends to underestimate class-race connections, assuming that our societies are horizontal rather than vertical mosaics. At the level of practice, in many instances multicultural education has become tokenism, taking the form of superficial exercises that put excessive attention on the three F s of food, folklore and festivities. M oreover, it is pertinent to remember that schools impart citizenship education explicitly (through the official curriculum, extra-curricular activities and school governance), but also through the hidden curriculum of rituals, regulations and informal interactions. This means that, like other educational practices, a progressive multicultural curriculum may be contradicted by exclusionary or discriminatory informal relations.

The word 'multiculturalism', by definition, simply recognizes a matter of fact: the co-existence of various cultural groups in the same society according to basic shared values and norms that ensure sufficient levels of cohesion. The recognition of cultural diversity is certainly meritorious, but citizenship education could move a step forward by appealing to the notion of interculturalism, which explicitly asserts the need for relationship, dialogue, reciprocity and interdependence. While 'multiculturalism' denotes a reality of mutual recognition that is not always due to voluntary dispositions, 'interculturalism' implies a desire, a pedagogical intentionality for mutual enrichment. Beyond differences of semantics, a citizenship education for the $21^{\text {st }}$ century should not be only about tolerating or cel ebrating each other, but also about nurturing dynamic exchanges based on interaction, openness and effective solidarity while recognizing power relations. Citizenship education should integrate the best traditions of multicultural and intercultural education to develop political and pedagogical strategies that contribute to overcome discrimination, racism and ethnocentrism, and to nurture genuine, inclusive dialogue among cultural groups.

\section{From preparation for the public sphere to inclusiveness}

O ur fourth proposition is that a twenty-first century model of citizenship education should overcome the private/public dichotomy, promoting democracy and inclusiveness in public spaces as well as in families, workplaces, unions, and other institutions, which are typically considered private domains. The twentieth century conceptualization of citizenship has been focused primarily on the public sphere. By framing a universal concept of citizenship constructed on the attributes, identities and practices of male subjects, gendered relations and the private sphere have been neglected. Following insights from feminist political theory, a twenty-first century conceptualization of citizenship should recognize that the personal is political, and that, through an institutionalized sexual contract, public equality is often premised on private inequalities. This conceptualization should go beyond the corset of the Wolstonecraft dilemma, nurturing new and inclusive relations and practices in both public and private spaces that recognize gender differences while ensuring inclusiveness and equity. It should also go beyond the idea of quotas for women in formal politics, or strategies to empower women to play male politics. 
From fundamentalism to peace building

The fifth proposition is that citizenship education for the twenty-first century should move away from fundamentalist ideologies and instead help to build a culture of peace. Two pillars of fundamentalism are manicheanism and self-righteousness. $M$ anicheanism is framed on a "good versus evil" mentality, and self-righteousness rests on the dangerous illusion that our view of reality is the only one. Today, in a context of increasing militarization, occupations, terrorism, civil wars and genocidal acts, it is urgent for citizenship education to advance pedagogical strategies to promote cooperation, dialogue, and a sustainable peace that is based on justice. It is obvious that citizenship education alone cannot bring peace to our planet, yet it can make a valuable contribution to create the subjective conditions for more peaceful situations. This includes the development of competencies for peacemaking, conflict resolution, healing, reconciliation and reconstruction. It also includes an understanding of $G$ andhianbased nonviolent civil disobedience philosophies, strategies and skills. A peace-oriented citizenship education can foster the development of values, attitudes and skills to nurture peace within oursel ves and in our personal relationships, and to create the conditions for peace in our own communities and in the global community.

From school-based citizenship to learning communities

The sixth proposition is that citizenship education for the twenty-first century should expand its horizons, both in terms of curriculum content and pedagogical spaces, from an almost exclusive focus on schools, to the creation of inclusive learning communities engaged with a curriculum of life. This proposition calls to open the scope of the curriculum, the spaces of pedagogical interventions, and the ages of participant learners. This implies, to begin with, articulating coherently (through an interdisciplinary curriculum) different aspects of school life with relevant issues in the surrounding community, from job creation to garbage disposal to human rights abuses. It also implies nurturing democracy in schools, so that teachers and learners can practice democracy everyday instead of merely talking about it. This proposition also implies broadening the spaces of intervention, including many out-of-school sites that are not always considered as pedagogical spaces.

A possible strategy to start this would be to connect schools with other agencies and organizations like museums, libraries, neighbourhood associations, social clubs, community gardens, universities, cooperatives, community centres, political representatives, local media, arts and crafts clubs, and the like. Learning communities would work through reciprocal networks than through hierarchical, bureaucratic institutions, and schools could play a particularly dynamic role in igniting and maintaining those relationships. This strategy could help to integrate schools with out-of-school education, face-to-face interactions with electronic forums, and children with youth and adults and seniors in intergenerational projects. Although schools were designed for the needs of nineteenth century industrial production, they can still be important sites to nurture the active, democratic and ecological citizens required for the twenty-first century. Learning communities could complement this purpose by constituting new pedagogical and democratic spaces for schools, other institutions and surrounding 
communities to come together, share their knowledge, learn collectively, and promote local development and democratic governance.

\section{From formal to substantive democratic citizenship}

This proposition callsfor an expansion of curriculum content, which should include not only the description of formal citizenship, but also a critical analysis of the gap between formal and substantive democracies. This implies a shift from an emphasis on 'constitutional citizenship' to critical pedagogy. Learning the formalities of citizenship and democracy is certainly a good starting point for citizenship education. H owever, this should be the beginning and not the end of the educational process, as a curriculum centered on formal democracy has difficulties to explain the existence of structural inequalities and discriminatory practices. If only half of the articles of the 1948 Universal D eclaration of H uman Rights were realized, we would be living today in a much more just and livable world. The same applies to many national constitutions. It is important to study the principles guiding the functioning of democratic societies, as well as the civic, political and social citizenship rights to which everyone should be entitled, yet it is as important to understand why there is a gap between them and the realities of everyday life. In interpreting the reasons for this gap, the curriculum should examine the economic, social, cultural and political structures that pre vent the fulfillment of democratic ideals. This ranges from the impact of economic global ization and structural adjustment policies on citizens' quality of life (particularly in the majority world), to the analysis of the causes of any unjust situation and exclusionary dynamic at the national and local levels. In order to bridge the gap between formal and substantive democracies, and between theoretical citizenship rights and their enactment in practice, at some point the curriculum must address controversial issues such as the unequal distribution of wealth, or the influence of power on the media and the political system. It also must engage learners (and this bring us back to the first proposition) in concrete actions to narrow the distance between the ideal and the real world.

\section{About this issue}

It is in the context of these issues, challenges and proposals that the articles in the present volume attempt to provide a contribution to the field by examining concrete meanings and practices, both in national and international contexts. We believe that the articles of this collection - which constitute a selection of those presented at the last two CERN conferences - help to shed light on citizenship education models and practices, both inside and outside schools. The forms and approaches to citizenship education taken by the authors in this journal demonstrate a range of pedagogical approaches and spaces to citizenship education, including issues of identity, interpersonal relations, intercultural understanding, lifelong learning, peace-building and political engagement. The volume is organized in three sections: 1) conceptual models of citizenship and citizenship education; 2) immigrants, identity and civic engagement; and 3) schools, teachers and learners. 


\section{Conceptual models of citizenship and citizenship education}

The renewed interest in developing citizenship education that we are witnessing today, claims Vigneault, is reminiscent of the philosophical interest of ancient G reeks for the very same questions: the development of the citizen ('la formation du citoyen' in the French original). The devel opment of the citizen is a philosophical project with a pedagogical challenge: the acquisition of civic values and competencies. Vigneault claims that critical thinking, a transferable civic competence, is the pillar for the development of all other civic competencies. D rawing from Socrates, Vigneault argues that a critical spirit begins with an examination of our own assumptions. O nly when we take some distance from our own knowledge and begin to doubt, can we understand our own ignorance (the basis of the Socratic irony), and engage in genuine dial ogue with others.

In the second article of this section, Westheimer and Kahne provide a conceptual framework that identifies three main approaches to citizenship education. They argue that the competing conceptions of citizenship education are based on political interests, and that each conception has different pedagogical implications for teaching democracy. Schools have been considered important sites for citizenship education, particularly due to the strong correlation (put forward by Almond and Verba in The Civic Culture in the early 1960s and confirmed by many subsequent studies) between educational achievement, political attitudes and expected participation. Based on a study of citizenship education programs in the U .S., Westheimer and Kahne outline three conceptions of the "good" citizen: personally responsible, participatory, and justice oriented. They contend that the pedagogical choices we make in curriculum design are based on implicit values, and have important consequences for the type of society we ultimately help to build.

In the last article of this section, Folgueiras examines theoretical and practical issues in designing an adult education program supporting active citizenship for adult female immigrants in Catalonia, Spain. Using the insights of gender, multiculturalism, and deliberation theories, among others, Folgueiras designs a conceptual map for communities to move from simpletolerance to mutual recognition. She makes a case for using a participatory action research approach that engages the participants in the design and evaluation of the program. Folgueiras understands citizenship as participation in the political life of the nation and citizenship education as preparation for this participation.

\section{Immigrants, identity and civic engagement}

$O$ pening this section, Long and H ughes present a study on the role of prior political knowledge on Latin American immigrants' political participation in Canada, and the challenges for immigrants to participate fully in politics. In Canada, a country that is presently struggling with the meaning of its own national identity and citizenship vis-àvis its relationship with the U.S. and as a member of the world community, the theme of citizenship is particularly relevant. As the immigration laws have led to greater ethnic and religious diversity over the past 30 years, multicultural citizenship has become an increasingly important topic. In this study, Long and $\mathrm{H}$ ughes point out some of the weaknesses in $\mathrm{C}$ anadian multiculturalism by examining the integration of immigrants 
as a restrictive manifestation of citizenship. They found that, despite immigrants' desire to participate in politics, they do not perceive themselves to be well integrated into Canadian political life, particularly in terms of electoral politics, and feel restricted to participation in grassroots politics.

Whereas Long and $H$ ughes focus on Latin American immigrants, H ebert, Le, Sun and Berti provide new insights on immigrant youth, particularly on the ways young newcomers build relationships that bear on their access to sources of political capital. $U$ sing network theory to guide their research, and relying on drawings as a methodological tool, they explore the notion of relational citizenship. According to the authors, immigrant youth develop vertical, hierarchical and competitive orientations to friendship simultaneously. They understand friendship as a mutually alternating resource that allows for weak ties of acquaintances, and facilitates social mobility, the transportation of information, and integration. They suggest that the benefits gained from developing close friendships in schools in order to access knowledge and skills is a necessary but insufficient condition to assure integration and participation in society. They also found that schools are important socializing spaces in which informal relationships position students (both native-born and immigrant) peripherally or centrally to networks of citizenship.

\section{Schools, teachers and learners}

The role of schools in citizenship building is also analyzed by Levesque, who addressed this in relation to issues of identity and multiculturalism. In C anada, these issues are at the center of contestation over the rights and roles of Aboriginal and Francophone communities within the federalist (mostly Anglophone) framework. Contributing to the scarce literature on educational research examining differences between Francophone and Anglophone communities, Levesque compares the effect of regional culture as embodied in social studies classes on the development of students' understanding of citizenship in two Canadian provinces: British Columbia and Q uebec. These distinctions are highlighted in education due to the decentralized organization of the Canadian education system, which gives autonomy over educational policy and educational provision to individual provinces. Levesque finds that the differences accorded to the two groups of students about citizenship center on the issue of identity and the longstanding tension in Q uebec between national and cultural identities.

In the context of the Israeli-Palestinian conflict, Feuerverger examines the role of schools in contested nationhood and citizenship. She explores the experience of an intercultural school in promoting tolerance, dialogue and peace-building among two peoples with a long history of animosity and mistrust. The article uses an ethnographic approach to examine the ways in which an intercultural school can teach about peace and conflict resolution to I sraeli and Palestinian students using dialogue. The school, aptly named ' $\mathrm{O}$ asis of Peace', was founded by Palestinians and Jews who aimed at demonstrating -with the power of example the possibilities for living in peace. The article examines the educational challenges to breaking down barriers by looking at interrelationships that exist in the school. The author recognizes the complexity of the issue, which has psychological, social and personal dimensions. 
In the last article of this section, Schugurensky and Myers explore the connections between learning and teaching civics by relating teachers learning experiences to their pedagogical approaches. Conceiving learning as a lifelong and lifewide process, and employing interviews with teachers of the new 0 ntario civics course, they set out to examine the differential impact (positive or negative) on teaching of diverse citizenship learning 'spaces' that teachers encounter throughout their lives, from early primary socialization to the present. They identified ninelearning settings, and confirmed the important rolethat informal and experiential learning play in the development of civic knowledge, skills, attitudes, and values. In terms of the development of civic teaching competencies, a particularly influential way of learning by doing was 'learning by teaching'.

In closing, we hope that the eight works in this volume provide some insights to advance the theory, research and practice of citizenship education. W hile the authors approach the field of citizenship education from diverse perspectives and disciplinary approaches, they share a collective concern with the emancipatory dimension of citizenship education. To different degrees, all authors engage with past scholarship in the field but also point out new directions for its expansion. We trust that this collection serves as a modest contribution to the understanding of citizenship education today, and to the development of a planetary citizenship education that seriously embraces democracy as a system and as a way of life.

D aniel Schugurensky and John P. M yers, Toronto, Fall 2003 
10 Encounters/Encuentros/Rencontres 